\title{
The structure of online consumer communication networks
}

Citation for published version (APA):

Harmsen - van Hout, M. J. W., Herings, P. J. J., \& Dellaert, B. G. C. (2006). The structure of online consumer communication networks. METEOR, Maastricht University School of Business and Economics. METEOR Research Memorandum No. 028 https://doi.org/10.26481/umamet.2006028

Document status and date:

Published: 01/01/2006

DOI:

10.26481/umamet.2006028

Document Version:

Publisher's PDF, also known as Version of record

\section{Please check the document version of this publication:}

- A submitted manuscript is the version of the article upon submission and before peer-review. There can be important differences between the submitted version and the official published version of record.

People interested in the research are advised to contact the author for the final version of the publication, or visit the DOI to the publisher's website.

- The final author version and the galley proof are versions of the publication after peer review.

- The final published version features the final layout of the paper including the volume, issue and page numbers.

Link to publication

\footnotetext{
General rights rights.

- You may freely distribute the URL identifying the publication in the public portal. please follow below link for the End User Agreement:

www.umlib.nl/taverne-license

Take down policy

If you believe that this document breaches copyright please contact us at:

repository@maastrichtuniversity.nl

providing details and we will investigate your claim.
}

Copyright and moral rights for the publications made accessible in the public portal are retained by the authors and/or other copyright owners and it is a condition of accessing publications that users recognise and abide by the legal requirements associated with these

- Users may download and print one copy of any publication from the public portal for the purpose of private study or research.

- You may not further distribute the material or use it for any profit-making activity or commercial gain

If the publication is distributed under the terms of Article $25 \mathrm{fa}$ of the Dutch Copyright Act, indicated by the "Taverne" license above, 
Marjolein J.W. Harmsen - van Hout,

P. Jean-Jacques Herings, Benedict G.C. Dellaert

The Structure of Online Consumer

Communication Networks

$\mathrm{RM} / 06 / 028$

JEL code: A14, C79

\section{METEबR}

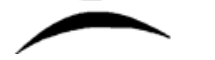

Maastricht research school of Economics

of TEchnology and ORganizations

Universiteit Maastricht

Faculty of Economics and Business Administration P.O. Box 616

NL - 6200 MD Maastricht

phone : ++31433883830

fax $\quad$ : ++31433884873 



\title{
The Structure of Online
}

\section{Consumer Communication Networks}

\author{
Marjolein J.W. Harmsen - van Hout* P. Jean-Jacques Herings ${ }^{\dagger}$ \\ Benedict G.C. Dellaert ${ }^{\ddagger}$
}

July 12,2006

\begin{abstract}
In this paper we study the structure of the bilateral communication links within Online Consumer Communication Networks (OCCNs), such as virtual communities. Compared to the offline world, consumers in online networks are highly flexible to

*Department of Marketing, Faculty of Economics and Business Administration, Maastricht University, P.O. Box 616, 6200 MD Maastricht, The Netherlands, e-mail: m.vanhout@mw.unimaas.nl, fax: +314338

${ }^{\dagger}$ Department of Economics, Faculty of Economics and Business Administration, Maastricht University, P.O. Box 616, 6200 MD Maastricht, The Netherlands, e-mail: p.herings@algec.unimaas.nl, fax: +314338 84 878, phone: +31 433883 824; +31433883636

${ }_{\ddagger}^{\ddagger}$ Department of Business Economics, Marketing Section, School of Economics and Business Economics, Erasmus University, P.O. Box 1738, 3000 DR Rotterdam, The Netherlands, e-mail: dellaert@few.eur.nl, fax: +31 10408 9169, phone: +31 104081353
\end{abstract} 84 918, phone: +314338 83861 
choose their communication partners and little is known about how this affects communication exchange structures. We analyze these structures by using a general approach from the game-theoretic literature of social and economic network formation where individuals trade off the cost of forming and maintaining links against the potential rewards of doing so, which results in a stable network structure. In our analysis, a combination of aspects common to OCCNs is incorporated that has not been investigated in this literature until now. First, the negative externality of communication specificity is included in the sense that the more direct connections an individual has to maintain with other individuals, the less she is able to specify her attention per link within her total time available. Therefore, the additive value per individual of her communications declines with an increasing number of links, and she also derives less additive value per individual from others with an increasing number of links. Second, a distinction is made between the social and informational value of communication, where informational communication value is assumed to be transferable via indirect links, whereas social communication value is not transferable. Analytical results are derived by using the concept of pairwise stability. A tendency towards fragmented pairwise stable structures - consisting of small, disjoint (star) components - is discovered, which can be attributed to the joint effect of the two aspects mentioned. We demonstrate that only some of the pairwise stable structures provide optimal welfare (total payoffs), and that the relative focus on informational versus social value of communication affects this welfare.

JEL Classification: A14, C79

Keywords: Consumers, Communication Specificity, Social vs. Informational Communication Value, Online Network Formation, Game Theory 


\section{Introduction}

The large-scale availability of high-speed Internet allows a growing number of consumers to easily communicate with like-minded individuals based on shared interests around for example products, consumption activities, or personal conditions (e.g., Algesheimer, Dholakia, and Herrmann, 2005; Dellarocas, 2003). Web sites such as www.saabnet.com, www.ediets.com/community/, and www.healthboards.com offer online platforms on which consumers share information that supports their decisions. We refer to the individuals and their interactions on such websites as Online Consumer Communication Networks (OCCNs).

In this paper we study the structure of the bilateral communication links within OCCNs. Compared to the offline world, consumers in online networks are highly flexible to choose their communication partners and little is known about how this affects communication structures. In our analysis, a combination of aspects common to OCCNs is incorporated that has not been investigated in the literature before. First, we present a game-theoretical model for communication network formation that features link specificity in the sense that the more direct connections an individual has to maintain with other individuals, the less she is able to specify her attention per link within her total time available. Therefore, her additive value per link for others declines and she also derives less additive value from links with others. Second, we realize that as soon as the value derived from communication is not only social but also contains an informational component, this value is transferable via indirect links. This is more prominently so in online communication than in offline communication since information can more easily be forwarded to others. However, also in this forwarding process, specificity plays a role. The combination of these two features, specificity and transferability, 
has a fragmentizing effect on network structure and consequently welfare implications, which means that the informational versus social orientation of an OCCN could be of managerial concern.

The paper is structured as follows: Section 2 shortly reviews the existent literature and illustrates our contribution, Section 3 deals with the case of communication having social value only in order to illustrate the impact of link specificity on structure, Section 4 deals with the case of communication from which both social and informational value is derived in order to illustrate the impact of value transferability on structure, Section 5 deals with welfare implications, and Section 6 concludes and offers directions for further research.

\section{Literature review}

Research in the emerging area of online communication networks initially was largely conceptual in nature (e.g., Dellarocas, 2003; Hagel and Armstrong, 1997; Wellman et al., 1996; Butler, 2001). More recently however, scholars have focused on the question why individuals choose to participate in, and contribute to OCCNs highlighting various individual motives including informational value, social value and self discovery (e.g., Dholakia et al., 2004; McLure Wasko and Faraj, 2005). Social influence variables such as identification with the group (social identity) and group norms have also been found to play a role in individuals' participation behavior (Bagozzi and Dholakia, 2002).

The current paper takes a complementary approach to understanding OCCNs by focusing on the structure of the underlying networks. This structure can determine important outcome variables such as the extent to which social and informational value is shared 
throughout the network, and how it is distributed.

This type of analysis is related to work in organization research that has addressed questions like the degree of centralization in virtual organizations (e.g., Ahuja and Carley, 1999). In contrast to this work in organization however, we address the case in which individuals participate in an OCCN on a voluntary basis and do not necessarily share the same common purpose and/or obtain compensation from their organizations for participating, as do, for example, virtual teams (Lipnack and Stamps, 2000).

For this reason, and because of earlier research findings emphasizing that individuals may have various motives for participation in OCCNs, we allow for two categories of individual participation value in our analysis: (1) social and (2) informational value. These two categories are largely representative of most individual-level benefits of participating in OCCNs . Social value is related to the fact that individuals may simply enjoy communicating with others (for example because they find it entertaining, or because they feel it enhances their self-worth; e.g., Hennig-Thurau et al., 2004). Informational value refers to the fact that consumers may obtain new valuable knowledge from other consumers when they communicate in an online exchange. Typically, informational communication value or knowledge can be transferred relatively easily to third parties through indirect links, whereas social communication value is even more personal and therefore hardly transferable. This transferability is an example of a positive network externality (e.g., Asvanund et al., 2004).

To analyze the underlying structure of OCCNs we develop an analytical model for the formation of links in online OCCNs that allows us to understand the relative impact of social and informational member orientation on the network structure in an OCCN. In this model, we interpret the formation of OCCNs as a type of non-cooperative network formation pro- 
cess in which individuals choose to create links, only if the participants in the link benefit from doing so (Jackson and Wolinsky, 1996). This way of modelling network formation is more appropriate in the online context than in the offline context, since in OCCN formation, it is much easier for individuals to strategically choose their communication contacts compared to the offline case. The reason is that in the offline world consumers are much more constrained by geographical distance and by social networks that are already in place (e.g., family structures).

We distinguish between two types of communication in OCCNs. First, an individual can choose to communicate to all other individuals simultaneously. In this case no personal, bilateral interaction takes place between individuals (e.g., a question is placed on a notice board). We do not interpret such communication as a bilateral exchange link between individuals. For example, as soon as an individual enters or subscribes to a virtual community or e-mail list, this communication becomes available to her. In our analysis we focus on a second type of communication, that requires that two individuals decide to communicate to each other. In this case, individuals can choose to communicate with selected other participants. Since this communication is bilateral, we assume that only those participants involved in the communication can obtain direct value from it. This is due to the specificity of the exchanged text, that is unique for the relationship (the exchanged text may still be available to all other individuals as well and thus provide a common indirect value). The second type of communication is most relevant for explaining potential structural differences between networks because it differs between individuals. Therefore, we focus on it in our analysis.

In fact, this type of communication represents the main explanation for non-completeness 
of OCCNs because it is a source of negative externalities (e.g., Asvanund et al., 2004): the more direct connections an individual has to maintain with other individuals, the less she is able to specify her attention per link within her total time available. Therefore, her additive value for others declines and she herself also derives less additive value from others (Kvassov, 2002; Currarini, 2002; Jackson and Wolinsky, 1996).

\section{Social value}

Although we expect that OCCNs will typically combine social and informational value aspects in their communication, we first deal with the simpler case in which only social value is derived from communication. This approach allows us to illustrate the separate impact of link specificity on structure and welfare. The externalities of link formation are much more crucial in our context than in the co-author setting, which has been the subject of investigation in earlier research (Jackson and Wolinsky, 1996). In the communication context no benefits arise from individual contributions per se. The reason is that communication is only valuable if it is two-sided, whereas each co-author can write independently. The objective of this section therefore is to propose a model for network formation in OCCNs with only social value from communication. We also develop an appropriate stability concept for this case and the large category of stable network structures is characterized.

\subsection{Model}

Consider a community of agents $N=\{1, \ldots n\}, n \geq 3$. A direct link $g_{i, j}$ between agents $i$ and $j$ in this community $(i, j \in N ; i \neq j)$ can be interpreted as a virtual exchange relationship 
between $i$ and $j$ which is established if they both wish the link. Virtual exchange relationships are expressed by undirected links, for any two agents $i$ and $j, g_{i, j}=g_{j, i}$.

In case of an isolated relationship where communication has only social value, $j$ derives social value $V^{\mathrm{s}}>0$ from $i$. However, maintenance of the relationship between $i$ and $j$ costs time: both agents are assumed to divide their available sending time as well as their available receiving time equally among all their relationships, as a result of which the value $V^{\mathrm{s}}$ is divided proportionally. This is due to the fact that although the agents represent constant potential value for each other, time investment of both sender and receiver is needed in order to make the potential value specific and hence useful for the receiver. Therefore, the payoff for agent $i$ is given by

$$
\Pi_{i}(g)=\sum_{j \in N_{i}^{\mathrm{N}}(g)} \frac{V^{\mathrm{s}}}{\mu_{i}^{\mathrm{N}}(g) \cdot \mu_{j}^{\mathrm{N}}(g)}
$$

if $\mu_{i}^{\mathrm{N}}(g)>0$, and $\Pi_{i}(g)=0$ if $\mu_{i}^{\mathrm{N}}(g)=0$, where $g_{i, j}$ in link structure $g$ indicates with a 1 or a 0 whether $i$ is directly linked to $j$ or not (by definition, $g_{i, i}=0$, as agents do not establish communication links with themselves); $N_{i}^{\mathrm{N}}(g)$ is the set of agents with whom $i$ has a direct link, where agent $j$ is a neighbor of agent $i$ if $j \in N_{i}^{\mathrm{N}}(g)$, and $\mu_{i}^{\mathrm{N}}(g)=\left|N_{i}^{\mathrm{N}}(g)\right|$ is the number of neighbors of agent $i$, which can also be referred to as the degree of $i$; and $V^{\mathrm{s}}>0$ denotes the social value that $i$ derives from observing $j$ if all attention of the community were going to the social value of communication and neither $i$ nor $j$ were linked to any other agent. $^{1}$

\footnotetext{
${ }^{1}$ For comparison: the payoff function in the co-author model of Jackson and Wolinsky (1996) can be
} written as

$$
\Pi_{i}(g)=\sum_{j \in N_{i}^{\mathrm{N}}(g)}\left(\frac{V^{\mathrm{s}}}{\mu_{i}^{\mathrm{N}}(g)}+\frac{V^{\mathrm{s}}}{\mu_{j}^{\mathrm{N}}(g)}+\frac{V^{\mathrm{s}}}{\mu_{i}^{\mathrm{N}}(g) \cdot \mu_{j}^{\mathrm{N}}(g)}\right) .
$$


For the model thus described stable network structures can be predicted to emerge by using the concept of pairwise stability (Jackson and Wolinsky, 1996), where a network structure is stable if no single agent can strictly improve her payoff by deleting one of her direct links and no pair of agents can strictly improve her sum of payoffs while each of the two members is at least indifferent by creating a direct link between the two members. This concept differs from a Nash solution in the sense that it only assumes stability against deviations of exactly one link (which involves the permission of two agents in the case of link formation), whereas the Nash network is stable against individual deviations of any size. In our notation, we have the following definition.

Definition 1 (pairwise stability) The structure $g$ is pairwise stable if for all $i, j \in N$ with $g_{i, j}=1$ it holds that

$$
\Pi_{i}(g) \geq \Pi_{i}\left(g^{\prime}\right) \text { and } \Pi_{j}(g) \geq \Pi_{j}\left(g^{\prime}\right),
$$

where $g^{\prime}$ is such that $g_{i, j}^{\prime}=0$ and $g_{k, l}^{\prime}=g_{k, l}$ for all $\{k, l\} \neq\{i, j\}$, and for all $i, j \in N$ with $g_{i, j}=0$ it holds that

$$
\begin{gathered}
\Pi_{i}(g)>\Pi_{i}\left(g^{\prime}\right) \text { or } \\
\Pi_{j}(g)>\Pi_{j}\left(g^{\prime}\right) \text { or } \\
\left(\Pi_{i}(g)=\Pi_{i}\left(g^{\prime}\right) \text { and } \Pi_{j}(g)=\Pi_{j}\left(g^{\prime}\right)\right),
\end{gathered}
$$

where $g^{\prime}$ is such that $g_{i, j}^{\prime}=1$ and $g_{k, l}^{\prime}=g_{k, l}$ for all $\{k, l\} \neq\{i, j\}$.

\subsection{Results}

We prove that the class of pairwise stable network structures can be characterized by two easily verifiable conditions: (i) they are what we will call equal neighbor degree structures, 
meaning that everybody has at least one neighbor and every neighbor of agent $i$ has the same degree, and (ii) there is at most a difference of one between the degrees of agents in the same component.

Definition 2 (equal neighbor degree structure) A structure $g$ is an equal neighbor degree structure when it holds for each agent $i$ that $\mu_{i}^{\mathrm{N}}(g) \geq 1$ and for all agents $j, j^{\prime} \in N_{i}^{\mathrm{N}}(g)$ that $\mu_{j}^{\mathrm{N}}(g)=\mu_{j^{\prime}}^{\mathrm{N}}(g)$.

Definition 3 (component) A component in a network $g$ is a maximal set of agents $C \subseteq N$ who are connected to one another directly or indirectly, so for each $i, j \in C$ there exists a sequence of agents $k_{1}, \ldots, k_{m} \in C$ for whom it holds that $g_{i, k_{1}}=g_{k_{1}, k_{2}}=\ldots=g_{k_{m-1}, k_{m}}=$ $g_{k_{m}, j}=1$.

First consider the following lemma, in which the own degree of agent $i$ is denoted by $d_{i}$ and her neighbors' degree by $e_{i}$.

Lemma 4 A structure is pairwise stable if and only if it is an equal neighbor degree structure where it holds for each not directly linked pair of agents $i, j$ that

$$
e_{i} \leq d_{j} \text { or } e_{j} \leq d_{i} \text { or }\left(e_{i}=d_{j}+1 \text { and } e_{j}=d_{i}+1\right)
$$

Proof. $(\Longleftarrow)$ Assume that $g$ is an equal neighbor degree structure where for each not directly linked pair of agents $i, j$ Condition (2) is satisfied. The payoff of an agent $k$ as expressed in Eq. (1) reduces to $d_{k} V^{\mathrm{s}} /\left(d_{k} e_{k}\right)$, so agent $k$ does not want to delete a link, for

$$
d_{k} \frac{V^{\mathrm{s}}}{d_{k} e_{k}} \geq\left(d_{k}-1\right) \frac{V^{\mathrm{s}}}{\left(d_{k}-1\right) e_{k}}
$$


Moreover, no link between any pair of agents $i, j$ will be created if it will make either $i$ or $j$ strictly worse off or both of them equally well off. Therefore, no link is created if

$$
\begin{gathered}
\frac{V^{\mathrm{s}}}{e_{i}}>d_{i} \frac{V^{\mathrm{s}}}{\left(d_{i}+1\right) e_{i}}+\frac{V^{\mathrm{s}}}{\left(d_{i}+1\right)\left(d_{j}+1\right)} \quad \text { or } \\
\frac{V^{\mathrm{s}}}{e_{j}}>d_{j} \frac{V^{\mathrm{s}}}{\left(d_{j}+1\right) e_{j}}+\frac{V^{\mathrm{s}}}{\left(d_{i}+1\right)\left(d_{j}+1\right)} \quad \text { or } \\
\left(\frac{V^{\mathrm{s}}}{e_{i}}=d_{i} \frac{V^{\mathrm{s}}}{\left(d_{i}+1\right) e_{i}}+\frac{V^{\mathrm{s}}}{\left(d_{i}+1\right)\left(d_{j}+1\right)} \text { and } \frac{V^{\mathrm{s}}}{e_{j}}=d_{j} \frac{V^{\mathrm{s}}}{\left(d_{j}+1\right) e_{j}}+\frac{V^{\mathrm{s}}}{\left(d_{i}+1\right)\left(d_{j}+1\right)}\right) .
\end{gathered}
$$

The following illustrates that $e_{i} \leq d_{j}$ implies (3).

$$
e_{i} \leq d_{j} \Longrightarrow d_{i}\left(d_{j}+1\right)+e_{i}<\left(d_{i}+1\right)\left(d_{j}+1\right) \Longrightarrow \frac{d_{i}\left(d_{j}+1\right)+e_{i}}{\left(d_{i}+1\right)\left(d_{j}+1\right) e_{i}}<\frac{1}{e_{i}}
$$

Analogously, it can be shown that $e_{j} \leq d_{i}$ implies $(4)$, and $\left(e_{i}=d_{j}+1\right)$ and $\left(e_{j}=d_{i}+1\right)$ implies (5). Therefore, $g$ is pairwise stable.

$(\Longrightarrow)$ Assume that the structure $g$ is pairwise stable. First, suppose that there is an agent $i$ for whom it holds that $\mu_{i}^{\mathrm{N}}(g)=0$. Then her payoff would strictly improve from a link with some other agent $k$. It is obvious that also $k$ 's payoff would strictly increase if $\mu_{k}^{\mathrm{N}}(g)=0$, which contradicts pairwise stability, so consider the case where $\mu_{k}^{\mathrm{N}}(g) \geq 1$. The payoff of $k$ without this link equals

$$
\sum_{j \in N_{k}^{\mathrm{N}}(g)} \frac{V^{\mathrm{s}}}{\mu_{k}^{\mathrm{N}}(g) \cdot \mu_{j}^{\mathrm{N}}(g)}=\frac{V^{\mathrm{s}}}{\mu_{k}^{\mathrm{N}}(g)}\left(\sum_{j \in N_{k}^{\mathrm{N}}(g)} \frac{1}{\mu_{j}^{\mathrm{N}}(g)}\right),
$$

whereas by linking with $i$ it would become

$$
\begin{gathered}
\sum_{j \in N_{k}^{\mathrm{N}}(g)} \frac{V^{\mathrm{s}}}{\left(\mu_{k}^{\mathrm{N}}(g)+1\right) \cdot \mu_{j}^{\mathrm{N}}(g)}+\frac{V^{\mathrm{s}}}{\left(\mu_{k}^{\mathrm{N}}(g)+1\right) \cdot 1}=\frac{V^{\mathrm{s}}}{\left(\mu_{k}^{\mathrm{N}}(g)+1\right)}\left(\sum_{j \in N_{k}^{\mathrm{N}}(g)} \frac{1}{\mu_{j}^{\mathrm{N}}(g)}+1\right) \\
\geq \frac{V^{\mathrm{s}}}{\mu_{k}^{\mathrm{N}}(g)}\left(\sum_{j \in N_{k}^{\mathrm{N}}(g)} \frac{1}{\mu_{j}^{\mathrm{N}}(g)}\right) .
\end{gathered}
$$


The inequality follows from the observation that the expression before the inequality equals $V^{\mathrm{s}}$ times the average of the terms $1 / \mu_{j}^{\mathrm{N}}(g)$ and 1 , the expression after the inequality is equal to $V^{\mathrm{s}}$ times the average of the terms $1 / \mu_{j}^{\mathrm{N}}(g)$, and that $1 \geq 1 / \mu_{j}^{\mathrm{N}}(g)$ for all $j \in N_{j}^{\mathrm{N}}(g)$. This also contradicts pairwise stability. It follows that $\mu_{i}^{N}(g) \geq 1$ for all $i \in N$.

Secondly, suppose that for some $i$ it does not hold that $\mu_{j}^{\mathrm{N}}(g)$ is constant for all $j \in$ $N_{i}^{\mathrm{N}}(g)$. Then there is an agent $k \in N_{i}^{\mathrm{N}}(g)$ such that

$$
\mu_{k}^{\mathrm{N}}(g)>\frac{\sum_{j \in N_{i}^{\mathrm{N}}(g)} \mu_{j}^{\mathrm{N}}(g)}{\mu_{i}^{\mathrm{N}}(g)} .
$$

The payoff for $i$ is given by

$$
\sum_{j \in N_{i}^{\mathrm{N}}(g)} \frac{V^{\mathrm{s}}}{\mu_{i}^{\mathrm{N}}(g) \cdot \mu_{j}^{\mathrm{N}}(g)}=\frac{V^{\mathrm{s}}}{\mu_{i}^{\mathrm{N}}(g)} \sum_{j \in N_{i}^{\mathrm{N}}(g)} \frac{1}{\mu_{j}^{\mathrm{N}}(g)},
$$

whereas by deleting the link with $k$, the payoff for $i$ would become

$$
\begin{gathered}
\sum_{j \in N_{i}^{\mathrm{N}}(g)} \frac{V^{\mathrm{s}}}{\left(\mu_{i}^{\mathrm{N}}(g)-1\right) \cdot \mu_{j}^{\mathrm{N}}(g)}-\frac{V^{\mathrm{s}}}{\left(\mu_{i}^{\mathrm{N}}(g)-1\right) \cdot \mu_{k}^{\mathrm{N}}(g)}=\frac{V^{\mathrm{s}}}{\left(\mu_{i}^{\mathrm{N}}(g)-1\right)}\left(\sum_{j \in N_{i}^{\mathrm{N}}(g)} \frac{1}{\mu_{j}^{\mathrm{N}}(g)}-\frac{1}{\mu_{k}^{\mathrm{N}}(g)}\right) \\
>\frac{V^{\mathrm{s}}}{\mu_{i}^{\mathrm{N}}(g)} \sum_{j \in N_{i}^{\mathrm{N}}(g)} \frac{1}{\mu_{j}^{\mathrm{N}}(g)},
\end{gathered}
$$

where the last inequality follows immediately from the interpretation of the last two terms as $V^{\mathrm{s}}$ times an average of numbers $1 / \mu_{j}^{\mathrm{N}}(g)$. This contradicts pairwise stability, so $\mu_{j}^{\mathrm{N}}(g)=$ $\mu_{j^{\prime}}^{\mathrm{N}}(g)$ for all $j, j^{\prime} \in N_{i}^{\mathrm{N}}(g)$. We have shown that a pairwise stable structure is an equal neighbor degree structure.

Finally, suppose that there exists a not directly linked pair $i, j$ for which Condition (2) is not satisfied, implying

$$
e_{i} \geq d_{j}+1 \text { and } e_{j} \geq d_{i}+1 \text { and }\left(e_{i}>d_{j}+1 \text { or } e_{j}>d_{i}+1\right)
$$


Then $i$ and $j$ want to create a link between them, since this would cause the payoff for agent $i$ to become

$$
d_{i} \frac{V^{\mathrm{s}}}{\left(d_{i}+1\right) e_{i}}+\frac{V^{\mathrm{s}}}{\left(d_{i}+1\right)\left(d_{j}+1\right)} \geq d_{i} \frac{V^{\mathrm{s}}}{\left(d_{i}+1\right) e_{i}}+\frac{V^{\mathrm{s}}}{\left(d_{i}+1\right) e_{i}}=\frac{V^{\mathrm{s}}}{e_{i}}
$$

and for agent $j$ to become

$$
d_{j} \frac{V^{\mathrm{s}}}{\left(d_{j}+1\right) e_{j}}+\frac{V^{\mathrm{s}}}{\left(d_{j}+1\right)\left(d_{i}+1\right)} \geq d_{j} \frac{V^{\mathrm{s}}}{\left(d_{j}+1\right) e_{j}}+\frac{V^{\mathrm{s}}}{\left(d_{j}+1\right) e_{j}}=\frac{V^{\mathrm{s}}}{e_{j}}
$$

where according to the last condition in (7) at least one of the $\geq$ - signs is strict. This contradicts pairwise stability too. Therefore, $g$ is an equal neighbor degree structure with

$$
e_{i} \leq d_{j} \text { or } e_{j} \leq d_{i} \text { or }\left(e_{i}=d_{j}+1 \text { and } e_{j}=d_{i}+1\right)
$$

for each not directly linked pair of agents $i, j$.

Condition 2 in Lemma 4 can be further simplified as is shown in the following proposition.

Proposition 5 A structure is pairwise stable if and only if it is an equal neighbor degree structure where it holds for each pair of agents $k, l$ in the same component that

$$
\left|d_{k}-d_{l}\right| \leq 1
$$

Proof. Considering Lemma 4, it is sufficient to show that in an equal neighbor degree structure Condition 2 holds for each not directly linked pair $i, j$,

$$
e_{i} \leq d_{j} \text { or } e_{j} \leq d_{i} \text { or }\left(e_{i}=d_{j}+1 \text { and } e_{j}=d_{i}+1\right)
$$

if and only if Condition (8) is satisfied for each pair $k, l$ in the same component,

$$
\left|d_{k}-d_{l}\right| \leq 1
$$


$(\Longleftarrow)$ Assume an equal neighbor degree structure where for each pair $k, l$ in the same component Condition (8) is satisfied. Let $i, j$ be any not directly linked pair. If $e_{i} \leq d_{j}$, Condition (2) is satisfied. If not, then $e_{i}>d_{j}$ and we can derive by applying Condition (8) twice that

$$
e_{j} \leq d_{j}+1 \leq e_{i} \leq d_{i}+1
$$

If $e_{j} \leq d_{i}$, Condition (2) is satisfied. If not, then $e_{j}=d_{i}+1$ and Condition (2) is satisfied if it also holds that $e_{i}=d_{j}+1$. Suppose not, then $e_{i} \geq d_{j}+2$ and we can derive by applying Condition (8) that

$$
e_{i} \geq d_{j}+2 \geq\left(e_{j}-1\right)+2=d_{i}+2,
$$

which contradicts Condition (8). Therefore, Condition (2) is satisfied.

$(\Longrightarrow)$ Assume an equal neighbor degree structure where for each not directly linked pair $i, j$ Condition (2) is satisfied. Let $k, l$ be any pair in the same component. There exists at least one path between $k$ and $l$. Assume that the number of other agents on any of these paths is odd. Due to the equal neighbor degree structure it holds that

$$
e_{k}=e_{l} \text { and } d_{k}=d_{l},
$$

so Condition (8) is satisfied. Assume that the number of other agents on all of these paths is even. If the component consists of only $k$ and $l$, then Condition (8) trivially holds. Otherwise, there either exists an agent $m \in N_{l}^{\mathrm{N}}(g), m \neq k$, or there exists an agent $n \in N_{k}^{\mathrm{N}}(g), n \neq l$. Without loss of generality, assume the former is the case. Since all paths between $k$ and $l$ have an even number of other agents, it follows that $m$ is not directly linked to $k$. Due to the equal neighbor degree structure it holds that

$$
e_{k}=e_{m}, d_{m}=d_{k}, e_{m}=d_{l}, \text { and } e_{l}=d_{m} .
$$


Suppose that Condition (8) is not satisfied, so without loss of generality

$$
d_{l} \geq d_{k}+2
$$

Then it follows that

$$
e_{k} \geq d_{m}+2 \text { and } e_{m} \geq d_{k}+2
$$

which contradicts Condition (2) for $k, m$. Consequently, Condition (8) is satisfied.

The following examples illustrate the wide range of structures thus proven to be pairwise stable in the social value case.

Definition 6 (complete structure) A structure $g$ is complete if all agents are connected, so for all $i, j \in N$ it holds that $g_{i, j}=1$.

Corollary 7 The complete structure is pairwise stable, for it is an equal neighbor degree structure where it holds for each pair of agents $k, l$ in the single component that

$$
\left|d_{k}-d_{l}\right|=0
$$

Definition 8 (wheel structure) A structure $g$ is a wheel if it has exactly $n$ links and there exists a sequence of different agents $k_{1}, \ldots, k_{n} \in N$ for whom it holds that $g_{k_{1}, k_{2}}=g_{k_{2}, k_{3}}=$ $\ldots=g_{k_{n-1}, k_{n}}=g_{k_{n}, k_{1}}=1$.

Corollary 9 The wheel is pairwise stable, for it is an equal neighbor degree structure where it holds for each pair of agents $k, l$ in the single component that

$$
\left|d_{k}-d_{l}\right|=0
$$


Definition 10 (regular structure) A structure $g$ is regular if it exists of one component and for each agent $i \in N$ it holds that $d_{i}=d$.

Corollary 11 The regular structure is pairwise stable, for it is an equal neighbor degree structure where it holds for each pair of agents $k, l$ in the single component that

$$
\left|d_{k}-d_{l}\right|=0
$$

Example 12 A non-regular structure that is pairwise stable is given in Figure 1.

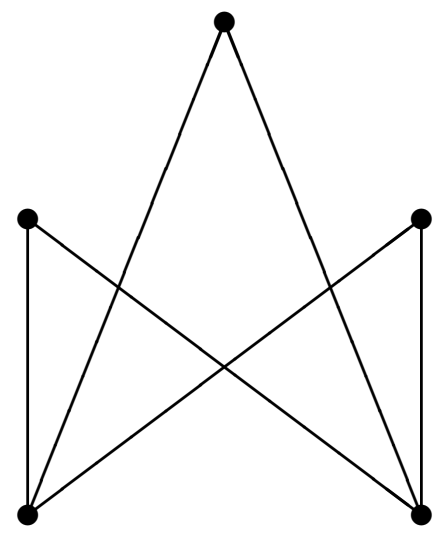

Figure 1: A non-regular pairwise stable structure.

Example 13 A structure consisting of multiple components that is pairwise stable is given in Figure 2.

Example 14 A "small world" is a structure with local clusters of highly interlinked agents together with agents that link the various clusters. As a consequence, although most agents are not directly connected, every agent is indirectly linked to every other agent by a relatively small number of steps. A "small world" structure that is pairwise stable is given in Figure 3. 

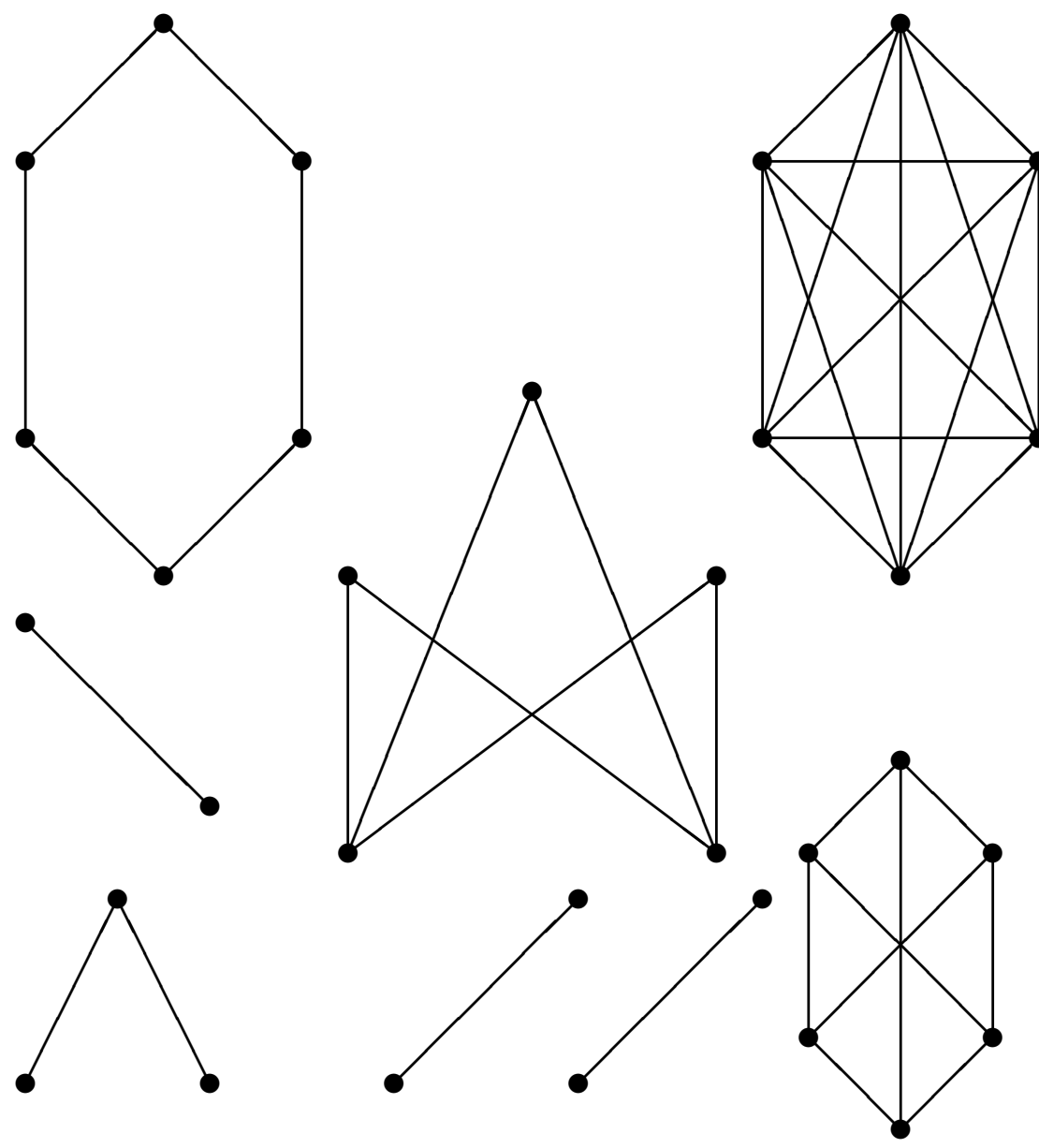

Figure 2: A multiple-component pairwise stable structure.

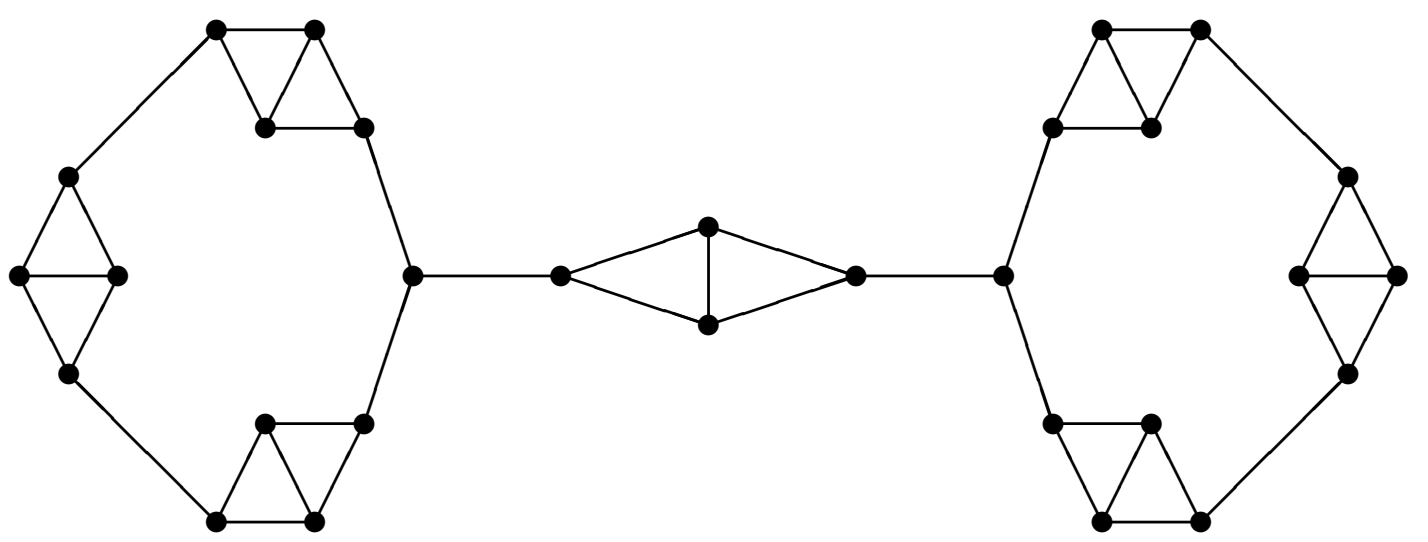

Figure 3: A "small world" pairwise stable structure. 


\section{Informational as well as social value}

This section now introduces the case in which both social and informational value is derived from communication. Thus, we can illustrate the impact of value transferability on structure and welfare along with the effect of specificity. More specifically, we make a distinction between social and informational value derived from communication, where only informational value is transferable through the network. For example, social value from communication between two Saab enthusiasts only exists for the two communication partners, but informational value (e.g, about a solution to a technical problem) can (partly) exist for others in the network. After proposing a model for network formation in this setting, the pairwise stable network structures will be characterized again. We demonstrate that the set of stable structures is much more limited in range than in the social value setting.

\subsection{Model}

Consider a community of agents $N=\{1, \ldots, n\}, n \geq 3$. A direct link $g_{i, j}$ between agents $i$ and $j$ in this community $(i, j \in N ; i \neq j)$ can be interpreted as a virtual exchange relationship between $i$ and $j$ which is established if they both wish the link. Virtual exchange relationships are expressed by undirected links, for any two agents $i$ and $j, g_{i, j}=g_{j, i}$, and $g_{i, i}=0$.

In case of an isolated relationship where communication has only social value, an agent derives social value $V^{\mathrm{s}}>0$ from the other agent. In case of an isolated relationship where communication has only informational value, an agent derives informational value $V^{\mathrm{i}}>0$ from the other agent. Both agents are assumed to give relative attention to informational and social value in the proportions $\alpha$ and $1-\alpha$ respectively, where $\alpha$ is assumed to be 
constant satisfying $0<\alpha<1^{2}$ Maintenance of the relationship between $i$ and $j$ costs time: both agents are assumed to divide their available sending time as well as their available receiving time equally among all their relationships, as a result of which the value $V^{\mathrm{i}}$ and $V^{\mathrm{s}}$ is divided proportionally. Moreover, informational value is, without any decay except for this time division, transferred to third parties through indirect links (paths of links), whereas social value is not transferable. Therefore, the payoff for agent $i$ is given by

$$
\begin{aligned}
\Pi_{i}(g)= & \alpha \sum_{j \in N_{i}(g)} \sum_{p \in \mathcal{P}_{i, j}(g)} \frac{V^{\mathrm{i}}}{\mu_{i}^{\mathrm{N}}(g) \cdot \mu_{j}^{\mathrm{N}}(g) \cdot \prod_{k \in \breve{P}}\left(\mu_{k}^{\mathrm{N}}(g)\right)^{2}} \\
& +(1-\alpha) \sum_{j \in N_{i}^{\mathrm{N}}(g)} \frac{V^{\mathrm{s}}}{\mu_{i}^{\mathrm{N}}(g) \cdot \mu_{j}^{\mathrm{N}}(g)},
\end{aligned}
$$

if $\mu_{i}^{\mathrm{N}}(g)>0$, and $\Pi_{i}(g)=0$ if $\mu_{i}^{\mathrm{N}}(g)=0$, where $\alpha$ is the proportion of communication through each link in the community that concerns product-, service- or firm-related information and $1-\alpha$ is the proportion of communication through each link in the community that concerns social interaction; $N_{i}(g)$ is the set of agents with whom $i$ has either a direct or an indirect link; $\mathcal{P}_{i, j}(g)$ is the set of paths between $i$ and $j$, where a path is defined as a sequence of consecutive edges without repeated nodes, and $\breve{P}$ is the set of agents on path $p$ between $i$ and $j$ excluding $i$ and $j$ themselves.

For the model thus described stable network structures are again predicted to emerge by using the concept of pairwise stability (Jackson and Wolinsky, 1996), where a network structure is stable if no single agent can strictly improve her payoff by deleting one of her direct links and no pair of agents can strictly improve her sum of payoffs while each of the

\footnotetext{
${ }^{2}$ The results in the case where the value derived from knowledge exchange are only informational $(\alpha=1)$ slightly differ from those in this mixed case $(\alpha<1)$. Specifically, it appears that structures also containing one four-agent star component can be pairwise stable.
} 
two members is at least indifferent by creating a direct link between the two members.

\subsection{Results}

It can be proven that the pairwise stable structures consist of small star components.

Definition 15 (star) A structure $g$ is a star if it has exactly $n-1$ links and there exists an agent $j$ for whom it holds that $g_{j, i}=1$ for all $i \neq j$. Similarly, a component $C$ is a star if it has exactly $|C|-1$ links and it contains an agent $j$ for whom it holds that $g_{j, i}=1$ for any other $i \in C$. Agent $j$ is called the center agent whereas the other agents are the periphery agents of the star.

First consider the following lemma in which it is shown that the star structure becomes unstable when there are more than three agents.

Lemma 16 The star structure is pairwise stable if and only if $n=3$.

Proof. From the star structure, it is not beneficial for any of the periphery agents to delete her link with the center agent as then her payoff will be zero. For the center agent, deleting a link with any of the periphery agents will provide her with the same payoff. To verify this result, it is crucial to observe that the center agent is not involved in any indirect links to other agents in star structures. Periphery agent $i$ will not create a link with another periphery agent $i$ ' if and only if

$$
\begin{gathered}
\alpha V^{\mathrm{i}}\left(\frac{1}{n-1}+\frac{(n-2)}{(n-1)^{2}}\right)+(1-\alpha) V^{\mathrm{s}} \frac{1}{n-1} \geq \\
\alpha V^{\mathrm{i}}\left(\frac{1}{2(n-1)}+\frac{1}{8(n-1)}+\frac{1}{4}+\frac{1}{4(n-1)^{2}}+\frac{(n-3)}{2(n-1)^{2}}+\frac{(n-3)}{8(n-1)^{2}}\right)
\end{gathered}
$$




$$
\begin{gathered}
+(1-\alpha) V^{\mathrm{s}}\left(\frac{1}{2(n-1)}+\frac{1}{4}\right) \\
\Longleftrightarrow \alpha V^{\mathrm{i}}(4-n)+(1-\alpha) V^{\mathrm{s}}(3-n) \geq 0 \Longleftrightarrow n \leq 3 .
\end{gathered}
$$

Since we assumed societies to consist of at least three agents, it holds that $n=3$.

Now the following proposition can be proven.

Proposition 17 A structure is pairwise stable if and only if it consists of disjoint star components of two or three agents.

Proof. $(\Longleftarrow)$ It is not beneficial for any of the periphery agents in a star component to delete her single link as then her payoff will be zero. Equivalently, for the center agent in a three-agent component, deleting a link with any of the two periphery agents is not beneficial as it will provide her with the same payoff.

With respect to link creation, apart from links between periphery agents from the same star that are eliminated by Lemma 16, the following cases $(a)-(f)$ exist:

\begin{tabular}{|ll|c|c|c|}
\cline { 2 - 5 } \multicolumn{1}{l|}{} & 2 & $3 \mathrm{c}$ & $3 \mathrm{p}$ \\
\hline 2 & (pair agent) & $(a)$ & $(b)$ & $(c)$ \\
\hline $3 \mathrm{c} \quad$ (center agent of three-agent star) & $\mathrm{x}$ & $(d)$ & $(e)$ \\
\hline $3 \mathrm{p} \quad$ (periphery agent of three-agent star) & $\mathrm{x}$ & $\mathrm{x}$ & $(f)$ \\
\hline
\end{tabular}

For each of these cases, it can be proven by evaluating the payoffs with and without the link that no link will be created: in case $(a)$, a pair agent would get payoff

$$
\alpha V^{\mathrm{i}}\left(\frac{1}{2}+\frac{1}{4}+\frac{1}{8}\right)+(1-\alpha) V^{\mathrm{s}}\left(\frac{1}{2}+\frac{1}{4}\right) \leq \alpha V^{\mathrm{i}}+(1-\alpha) V^{\mathrm{s}},
$$

in case $(b)$, the pair agent would get payoff

$$
\alpha V^{\mathrm{i}}\left(\frac{1}{2}+\frac{1}{6}+\frac{1}{18}+\frac{1}{18}\right)+(1-\alpha) V^{\mathrm{s}}\left(\frac{1}{2}+\frac{1}{6}\right)<\alpha V^{\mathrm{i}}+(1-\alpha) V^{\mathrm{s}},
$$


in case $(c)$, the pair agent would get payoff

$$
\alpha V^{\mathrm{i}}\left(\frac{1}{2}+\frac{1}{4}+\frac{1}{16}+\frac{1}{32}\right)+(1-\alpha) V^{\mathrm{s}}\left(\frac{1}{2}+\frac{1}{4}\right)<\alpha V^{\mathrm{i}}+(1-\alpha) V^{\mathrm{s}},
$$

in case $(d)$, a center agent would get payoff

$$
\begin{aligned}
& \alpha V^{\mathrm{i}}\left(\frac{1}{3}+\frac{1}{3}+\frac{1}{9}+\frac{1}{27}+\frac{1}{27}\right)+(1-\alpha) V^{\mathrm{s}}\left(\frac{1}{3}+\frac{1}{3}+\frac{1}{9}\right) \\
\leq & \alpha V^{\mathrm{i}}\left(\frac{1}{2}+\frac{1}{2}\right)+(1-\alpha) V^{\mathrm{s}}\left(\frac{1}{2}+\frac{1}{2}\right),
\end{aligned}
$$

in case $(e)$, the center agent would get payoff

$$
\begin{aligned}
& \alpha V^{\mathrm{i}}\left(\frac{1}{3}+\frac{1}{3}+\frac{1}{6}+\frac{1}{24}+\frac{1}{48}\right)+(1-\alpha) V^{\mathrm{s}}\left(\frac{1}{3}+\frac{1}{3}+\frac{1}{6}\right) \\
< & \alpha V^{\mathrm{i}}\left(\frac{1}{2}+\frac{1}{2}\right)+(1-\alpha) V^{\mathrm{s}}\left(\frac{1}{2}+\frac{1}{2}\right),
\end{aligned}
$$

and in case $(f)$, a periphery agent would get payoff

$$
\begin{aligned}
& \alpha V^{\mathrm{i}}\left(\frac{1}{4}+\frac{1}{4}+\frac{1}{8}+\frac{1}{16}+\frac{1}{32}\right)+(1-\alpha) V^{\mathrm{s}}\left(\frac{1}{4}+\frac{1}{4}\right) \\
\leq & \alpha V^{\mathrm{i}}\left(\frac{1}{2}+\frac{1}{4}\right)+(1-\alpha) V^{\mathrm{s}} \frac{1}{2} .
\end{aligned}
$$

$(\Longrightarrow)$ For this part of the proof, we need some extra notation. The payoff function in (10) can be rewritten as

$$
\Pi_{i}(g)=\frac{1}{\mu_{i}^{\mathrm{N}}(g)} \sum_{j \in N_{i}^{\mathrm{N}}(g)} T_{i, j}(g),
$$

where $T_{i, j}(g)$ is the total payoff that $j$ transmits to $i$ via her direct link with $i$. Formally,

$$
\left.\begin{array}{rl}
T_{i, j}(g)=\alpha\left(\frac{V^{\mathrm{i}}}{\mu_{j}^{\mathrm{N}}(g)}+\sum_{j^{\prime} \in N_{j}(g) \backslash\{i\}} \sum_{\substack{p \in \mathcal{P}_{j, j^{\prime}}(g) \\
i \notin \breve{P}}} \frac{V^{\mathrm{i}}}{\mu_{j^{\prime}}^{\mathrm{N}}(g) \cdot\left(\mu_{j}^{\mathrm{N}}(g)\right)^{2} \cdot \prod_{k \in \breve{P}}\left(\mu_{k}^{\mathrm{N}}(g)\right)^{2}}\right. \\
+(1-\alpha) \frac{V^{\mathrm{s}}}{\mu_{j}^{\mathrm{N}}(g)} .
\end{array}\right)
$$


Assume that $g$ is a pairwise stable structure. Let $i$ be an agent in $g$ and $k \in N_{i}^{\mathrm{N}}(g)$ be such that

$$
T_{i, k}(g)=\min _{j \in N_{i}^{\mathrm{N}}(g)} T_{i, j}(g)
$$

Suppose that there exists an agent $\ell \in N_{i}^{\mathrm{N}}(g)$ for whom it holds that

$$
T_{i, \ell}(g)>T_{i, k}(g)
$$

Deleting the link between $i$ and $k$ results in structure $g^{\prime}$, where it holds that

$$
T_{i, j}\left(g^{\prime}\right) \geq T_{i, j}(g), \forall j \in N_{i}^{\mathrm{N}}\left(g^{\prime}\right)
$$

since $k$, to whom $j$ might be (in)directly linked, has one costly direct link less, so more informational value might flow from $j$ to $i$ via $k$. The payoff for $i$ then becomes

$$
\Pi_{i}\left(g^{\prime}\right)=\frac{1}{\mu_{i}^{\mathrm{N}}(g)-1} \sum_{j \in N_{i}^{\mathrm{N}}\left(g^{\prime}\right)} T_{i, j}\left(g^{\prime}\right)>\frac{1}{\mu_{i}^{\mathrm{N}}(g)} \sum_{j \in N_{i}^{\mathrm{N}}(g)} T_{i, j}(g)=\Pi_{i}(g),
$$

which contradicts pairwise stability of $g$. It follows that

$$
T_{i, j}(g)=T_{i, j^{\prime}}(g), \forall j, j^{\prime} \in N_{i}^{\mathrm{N}}(g) .
$$

Next, suppose that $g$ contains a cycle, meaning that there exists a sequence of agents $k_{1}, \ldots, k_{n} \in N$ for whom it holds that $g_{k_{1}, k_{2}}=g_{k_{2}, k_{3}}=\ldots=g_{k_{n-1}, k_{n}}=g_{k_{n}, k_{1}}=1$. Let $i$ be an agent in this cycle. Deleting the link with one of $i$ 's neighbors in the cycle, say $k$, results in $g^{\prime}$, where it holds for the other neighbor of $i$ in the cycle, say $m$, that

$$
T_{i, m}\left(g^{\prime}\right)>T_{i, m}(g),
$$

since $k$, to whom $m$ is (in)directly linked, has one costly direct link less, so more informational value flows from $k$ to $i$ via $m$. Moreover,

$$
T_{i, j}\left(g^{\prime}\right) \geq T_{i, j}(g), \forall j \in N_{i}^{\mathrm{N}}\left(g^{\prime}\right)
$$


The payoff for $i$ then becomes

$$
\begin{aligned}
\Pi_{i}\left(g^{\prime}\right) & =\frac{1}{\mu_{i}^{\mathrm{N}}(g)-1} \sum_{j \in N_{i}^{\mathrm{N}}\left(g^{\prime}\right)} T_{i, j}\left(g^{\prime}\right)>\frac{1}{\mu_{i}^{\mathrm{N}}(g)-1} \sum_{j \in N_{i}^{\mathrm{N}}\left(g^{\prime}\right)} T_{i, j}(g) \\
& =\frac{1}{\mu_{i}^{\mathrm{N}}(g)} \sum_{j \in N_{i}^{\mathrm{N}}(g)} T_{i, j}(g)=\Pi_{i}(g),
\end{aligned}
$$

where the second equality follows from Eq. (12). This implies that $g$ is not pairwise stable, leading to a contradiction. We have therefore shown that $g$ does not contain any cycle.

Suppose that $g$ consists of components that are not stars. Since we have already shown that $g$ contains no cycles, all components of $g$ are trees. In a tree the number of links is one less than the number of agents. Moreover, in a tree there is a unique path between any two agents. A tree that is not a star contains an agent, say $i$, with a neighbor $h$ that only has $i$ as a neighbor, and, moreover, $i$ is directly linked to an agent $j$ who has another neighbor different from $i$. According to Eq. (12) it holds that

$$
T_{i, h}(g)=T_{i, j}(g)
$$

Since $h$ has only one neighbor, $i$, it follows that

$$
T_{i, h}(g)=\alpha V^{\mathrm{i}}+(1-\alpha) V^{\mathrm{s}}
$$

We will now evaluate $T_{i, j}(g)$ and show it is smaller than $T_{i, h}(g)$. Think of $N_{h}(g)$ as a tree with $h$ as top agent. For players $k, k^{\prime} \in N_{h}(g)$, player $k^{\prime}$ is a subordinate of $k$, denoted $k^{\prime} \in S(k)$, if $k$ is on the unique path from $h$ to $k^{\prime}$. Player $k^{\prime}$ is a direct subordinate of $k$, denoted $k^{\prime} \in S^{\mathrm{N}}(k)$, if $k^{\prime}$ is a subordinate of $k$ and there is a link between $k$ and $k^{\prime}$. We now write

$$
T_{i, j}(g)=\alpha T_{i, j}^{\mathrm{i}}(g)+(1-\alpha) T_{i, j}^{\mathrm{s}}(g)
$$


where

$$
T_{i, j}^{\mathrm{s}}(g)=\frac{V^{\mathrm{s}}}{\mu_{j}^{\mathrm{N}}(g)} \leq \frac{V^{\mathrm{s}}}{2}
$$

and

$$
T_{i, j}^{\mathrm{i}}(g)=\frac{V^{\mathrm{i}}}{\mu_{j}^{\mathrm{N}}(g)}+\sum_{k \in S(j)} \frac{V^{\mathrm{i}}}{\mu_{k}^{\mathrm{N}}(g)\left(\mu_{j}^{\mathrm{N}}(g)\right)^{2} \prod_{k^{\prime} \in \breve{p}_{j, k}}\left(\mu_{k^{\prime}}^{\mathrm{N}}(g)\right)^{2}},
$$

where $p_{j, k}$ is the unique path between $j$ and $k$.

Consider $k \in S(i)$. We define the informational payoff that $k$ receives from its successors by

$$
U_{k}^{\mathrm{i}}(g)=\frac{1}{\mu_{k}^{\mathrm{N}}(g)} \sum_{k^{\prime} \in S^{\mathrm{N}}(k)} T_{k, k^{\prime}}^{\mathrm{i}}(g),
$$

where $T_{k, k^{\prime}}^{\mathrm{i}}(g)$ is defined analogously to $T_{i, j}^{\mathrm{i}}(g)$. We obtain a recursive relation by observing that

$$
T_{k, k^{\prime}}^{\mathrm{i}}(g)=\frac{V^{\mathrm{i}}+U_{k^{\prime}}^{\mathrm{i}}(g)}{\mu_{k^{\prime}}^{\mathrm{N}}(g)}
$$

We will show by induction that

$$
U_{k}^{\mathrm{i}}(g) \leq V^{\mathrm{i}}\left(\mu_{k}^{\mathrm{N}}(g)-1\right)
$$

from which it follows that

$$
T_{k, k^{\prime}}^{\mathrm{i}}(g) \leq \frac{V^{\mathrm{i}}+V^{\mathrm{i}}\left(\mu_{k^{\prime}}^{\mathrm{N}}(g)-1\right)}{\mu_{k^{\prime}}^{\mathrm{N}}(g)}=V^{\mathrm{i}}
$$

and, consequently,

$$
T_{i, j}^{\mathrm{i}}(g) \leq V^{\mathrm{i}}
$$

Let $K^{0}$ be the set of agents without subordinates. For $m \geq 1$, let $K^{m}$ be the set of agents with all subordinates in $K^{0} \cup \cdots \cup K^{m-1}$. Let $m^{\prime}$ be the smallest integer for which 
$j \in K^{m^{\prime}}$. First consider an agent $k$ in $K^{0}$, the set of agents without subordinates. Then $U_{k}^{\mathrm{i}}(g)=0=V^{\mathrm{i}}\left(\mu_{k}^{\mathrm{N}}(g)-1\right)$, so $(14)$ is satisfied.

Suppose that (14) holds for agents in $K^{m}, m<m^{\prime}$. Consider an agent $k \in K^{m+1}$.

$$
\begin{aligned}
U_{k}^{\mathrm{i}}(g) & =\frac{1}{\mu_{k}^{\mathrm{N}}(g)} \sum_{k^{\prime} \in S^{\mathrm{N}}(k)} T_{k, k^{\prime}}^{\mathrm{i}}(g) \\
& \leq \frac{1}{\mu_{k}^{\mathrm{N}}(g)} \sum_{k^{\prime} \in S^{\mathrm{N}}(k)}\left(\frac{V^{\mathrm{i}}+V^{\mathrm{i}}\left(\mu_{k^{\prime}}^{\mathrm{N}}(g)-1\right)}{\mu_{k^{\prime}}^{\mathrm{N}}(g)}\right) \\
& =\frac{\mu_{k}^{\mathrm{N}}(g)-1}{\mu_{k}^{\mathrm{N}}(g)} V^{\mathrm{i}} \leq \frac{1}{2} V^{\mathrm{i}}\left(\mu_{k}^{\mathrm{N}}(g)-1\right),
\end{aligned}
$$

so (14) holds for all $k \in S(j)$.

Combining (13) and (15) implies $T_{i, j}(g)<T_{i, h}(g)$, a contradiction to Eq. (12), so $g$ consists of star components only.

Lemma 16 implies that these stars have at most three agents. "Stars" of a single agent cannot be part of $g$, for it is always strictly beneficial for this single agent to create a link to the center agent of another star, whereas this center agent is indifferent or improves if she is isolated too.

Comparing these results to the social value case, clearly a smaller range of (fragmented) structures has thus been proven to be pairwise stable in the case where transferable informational value also plays a role. Specifically, complete, wheel, and regular structures are never pairwise stable and also the example structures in Figures 1, 2, and 3 are not stable anymore. This may seem counter-intuitive, since apparently transferability of information causes structures to become more fragmented and therefore less able to transfer information. The intuition behind this finding is that the specificity property of communication is now strong enough to prevent individuals from creating many links, because it is strengthened 
by the transferability of value. The co-author model of Jackson and Wolinsky (1996) also contained a type of specificity, but since it was not combined with value transferability, the resulting stable structures were not as fragmented. Similarly, the connections model of Jackson and Wolinsky contained value transferability, but since it was not combined with link specificity, the resulting structures are not fragmented at all. ${ }^{3}$

\section{Welfare}

In this section, the structural results from the previous sections are assessed by their impact on welfare issues. The welfare of a network structure is defined as the sum of payoffs for all agents. It will turn out that because of link specificity, the efficient structures are very fragmented, regardless of whether there is transferable informational value. Furthermore, the from a welfare point of view best and worst pairwise stable network structures are characterized (Sections 5.1 and 5.2). We also analyze differences in welfare due to variations in social versus informational orientation in the network (Section 5.3).

Definition 18 (welfare) The welfare provided by structure $g$ is given by

$$
W(g)=\sum_{i \in N} \Pi_{i}(g)
$$

Definition 19 (efficiency) The structure $g$ is more efficient than the structure $g^{\prime}$ if it holds

\footnotetext{
${ }^{3}$ Note that this proposition is similar to what Haller \& Sarangi (2003) find in their setting with one-sided link formation, Nash equilibrium and negative externalities on link reliability (p. 27). In contrast, most studies find less fragmented stable structures, e.g. Goyal \& Vega-Redondo (2004) find large star structures in their setting of structural holes.
} 
that

$$
W(g)>W\left(g^{\prime}\right)
$$

\subsection{Best pairwise stable structures}

In the social value case, there are many pairwise stable structures. These structures are not at all equivalent from a welfare point of view. The next proposition characterizes the most efficient structures.

Proposition 20 In the social value case, if $n$ is even, then the most efficient pairwise stable structures consist of pairs only. If $n$ is odd, then the most efficient pairwise stable structures consist of one three-agent star and furthermore only pairs.

Proof. Since

$$
\Pi_{i}(g)=\frac{V^{\mathrm{s}}}{\mu_{i}^{\mathrm{N}}(g)} \sum_{j \in N_{i}^{\mathrm{N}}(g)} \frac{1}{\mu_{j}^{\mathrm{N}}(g)},
$$

the highest possible payoff for player $i$ is obtained if $\mu_{j}^{\mathrm{N}}(g)=1$ for all $j \in N_{i}^{\mathrm{N}}(g)$. If $i$ belongs to a pair, then this condition holds, so a player in a pair obtains the highest payoff possible. The highest payoff possible is therefore equal to $V^{\mathrm{s}}$. If a structure consists of only pairs, then all players get the highest payoff possible, and as a consequence, also the welfare provided by the structure is maximized.

If $n$ is odd, then the structure cannot consist of pairs only. There should be at least one player, say $i$, with at least two neighbors. Since pairwise stable structures are equal neighbor degree structures, all neighbors of neighbors of $i$ have the same degree as $i$, and therefore a payoff equal to $V^{\mathrm{s}}$ divided by $\mu_{i}^{\mathrm{N}}(g)$. The sum of the payoffs of all players is therefore maximized if there is only one player with more than one neighbor, and this player should 
have two neighbors. The structure therefore consists of one three-agent star and furthermore only pairs.

It is not hard to show that in the social value case, the structures identified in Proposition 20 are the most efficient ones among all structures, pairwise stable or not. This conclusion does not differ when informational value is included in the analysis. Agents that are part of a pair obtain the highest payoff possible, $\alpha V^{\mathrm{i}}+(1-\alpha) V^{\mathrm{s}}$, so structures with many pairs achieve a high degree of efficiency. The next proposition characterizes the most efficient pairwise stable structures for the case with both social and informational value.

Proposition 21 In the case with both social and informational value $(0<\alpha<1)$, if $n$ is even, then the most efficient pairwise stable structures consist of pairs only. If $n$ is odd, then the most efficient pairwise stable structures consist of one three-agent star and furthermore only pairs.

Proof. Proposition 17 implies that all pairwise stable structures consist of disjoint star components of two or three agents. The payoff for an agent in a pair is

$$
\alpha V^{\mathrm{i}}+(1-\alpha) V^{\mathrm{s}}
$$

whereas the average payoff for an agent in a three-agent star is only

$$
\frac{5}{6} \alpha V^{\mathrm{i}}+\frac{2}{3}(1-\alpha) V^{\mathrm{s}}
$$

Welfare of the structure is maximized by having only pairs if $n$ is even, and one three-agent star and furthermore only pairs if $n$ is odd. 
The most efficient pairwise stable structures coincide in the social value case, and the case with social and informational value. The worst case scenarios, i.e. the least efficient pairwise stable structures, are considerably different, as is shown in the next subsection.

\subsection{Worst pairwise stable structures}

In the social value case, many pairwise stable structures exist that are not efficient. The worst-case scenario is described in the following proposition.

Proposition 22 In the social value case, the complete structure provides the lowest welfare of all pairwise stable structures.

Proof. Since

$$
\Pi_{i}(g)=\frac{V^{\mathrm{s}}}{\mu_{i}^{\mathrm{N}}(g)} \sum_{j \in N_{i}^{\mathrm{N}}(g)} \frac{1}{\mu_{j}^{\mathrm{N}}(g)},
$$

and since every player has at least one link in a pairwise stable structure, the lowest payoff possible for player $i$ is obtained if all players $j \in N_{i}^{\mathrm{N}}(g)$ have maximal degree $\mu_{j}^{\mathrm{N}}(g)=n-1$. It follows that the complete structure has the lowest welfare of all pairwise stable structures.

The worst-case scenarios for the situation with both social and informational value are described in the following proposition.

Proposition 23 In the case with both social and informational value $(0<\alpha<1)$,

(a) if $n \in\{3,6,9, \ldots\}$, a structure consisting of only three-agent stars provides lowest welfare of all pairwise stable structures, 
(b) if $n \in\{7,10, \ldots\}$, a structure consisting of two pairs and furthermore only three-agent stars provides lowest welfare of all pairwise stable structures,

(c) if $n \in\{5,8,11, \ldots\}$, a structure consisting of one pair and furthermore only threeagent stars provides lowest welfare of all pairwise stable structures.

Proof. Proposition 17 implies that all pairwise stable structures consist of disjoint star components of two or three agents. The payoff for an agent in a pair is

$$
\alpha V^{\mathrm{i}}+(1-\alpha) V^{\mathrm{s}}
$$

whereas the average payoff for an agent in a three-agent star is only

$$
\frac{5}{6} \alpha V^{\mathrm{i}}+\frac{2}{3}(1-\alpha) V^{\mathrm{s}}
$$

which implies (a), (b), and (c).

Note that the worst-case scenarios in the case with social and informational value are not as bad as the worst-case scenario in the social value case. For any value of $n, V^{\mathrm{i}}$, and $V^{\mathrm{s}}$, the least efficient pairwise stable structure achieves an efficiency of at least $2 / 3$ times the most efficient structure. In the social value case, for any value of $V^{\mathrm{s}}$, this ratio can be as bad as $\frac{1}{n-1}$, which tends to zero as $n$ grows large.

\subsection{Informational versus social orientation}

Apparently, there are welfare differences attached to structural differences in an OCCN and structural differences arise by its informational versus social orientation $(\alpha)$. Therefore, in the following propositions different levels of $\alpha$ are compared. A managerial implication is 
that the welfare level provided by an OCCN can be influenced depending on how strongly $\alpha$ can be influenced. In order to affect $\alpha$, communication network managers could think of modifying moderator tasks, entry policy, rules of conduct, and reward systems, hereby emphasizing social versus informational value.

Proposition 24 The worst-case scenario for social value $(\alpha=0)$ is worse than a worstcase scenario when also a marginal amount of transferable informational value is provided $(\alpha \downarrow 0) .4$

Proof. For $\alpha=0$, Proposition 22 shows that the complete structure is the worst-case scenario, which provides a total payoff of

$$
\frac{n}{n-1} V^{\mathrm{s}}
$$

For $0<\alpha<1$, Proposition 23 shows that the total payoff in the worst-case scenario is at least equal to

$$
n\left(\frac{5}{6} \alpha V^{\mathrm{i}}+\frac{2}{3}(1-\alpha) V^{\mathrm{s}}\right) \rightarrow n \frac{2}{3} V^{\mathrm{s}} \text { if } \alpha \downarrow 0 .
$$

Since $n \geq 3$, it holds that

$$
n \frac{2}{3} V^{\mathrm{s}}>\frac{n}{n-1} V^{\mathrm{s}}
$$

The question whether more emphasis on social aspects rather than informational aspects is justified when maximizing welfare, depends on the ratio between $V^{\mathrm{s}}$ and $V^{\mathrm{i}}$. We denote this ratio by $x$, so $V^{\mathrm{s}}=x V^{\mathrm{i}}$.

\footnotetext{
${ }^{4}$ Note that results for the informational case $(\alpha=1)$ can be derived analogously.
} 
Proposition 25 Consider the case with social and informational value $(0<\alpha<1)$. Then it holds that

(a) the higher $\alpha$ the better the best-case as well as the worst-case scenarios if $x<1$, and

(b) the lower $\alpha$ the better the best-case as well as the worst-case scenarios if $x>1 \frac{1}{4}{ }^{5}$

Proof. If $n$ is even, Proposition ?? implies that a structure consisting of only pairs is a best-case scenario, which provides a total payoff of

$$
V^{\mathrm{i}} n((1-x) \alpha+x)
$$

which is increasing in $\alpha$ if $x<1$ and decreasing in $\alpha$ if $x>1 \frac{1}{4}$. If $n$ is odd, Proposition ?? implies that a structure consisting of one three-agent star and furthermore only pairs is a best-case scenario, which provides a total payoff of

$$
V^{i}\left(\left(n-\frac{1}{2}-(n-1) x\right) \alpha+(n-1) x\right)
$$

which, since $n \geq 3$, is increasing in $\alpha$ if $x<1$ and decreasing in $\alpha$ if $x>1 \frac{1}{4}$. If $n=3,6,9, \ldots$ Proposition 23 implies that a structure consisting of only three-agent stars is a worst-case scenario, which provides a total payoff of

$$
V^{i} n\left(\left(\frac{5}{6}-\frac{2}{3} x\right) \alpha+\frac{2}{3} x\right)
$$

which is increasing in $\alpha$ if $x<1$ and decreasing in $\alpha$ if $x>1 \frac{1}{4}$. If $n=4,7,10, \ldots$, Proposition 23 implies that a structure consisting of two pairs and furthermore only three-agent stars is a worst-case scenario, which provides a total payoff of

$$
V^{i}\left(\left(\frac{5}{6} n+\frac{2}{3}-\left(\frac{2}{3} n+1 \frac{1}{3}\right) x\right) \alpha+\left(\frac{2}{3} n+1 \frac{1}{3}\right) x\right),
$$

\footnotetext{
${ }^{5}$ For $x$ between 1 and $1 \frac{1}{4}$, comparative statics depend on the value of $n$.
} 
which, since $n \geq 4$, is increasing in $\alpha$ if $x<1$ and decreasing in $\alpha$ if $x>1 \frac{1}{4}$. The proof for $n=5,8,11, \ldots$ is similar.

\section{Discussion and conclusion}

This paper has shown that the structure of bilateral communication links within an OCCN can be appropriately studied by using a general approach from the game-theoretic literature of social and economic network formation where individuals trade off the cost of forming and maintaining links against the potential rewards of doing so, which results in a stable network structure. A combination of aspects common to OCCNs was incorporated that has not been investigated in the literature until now. First, the negative externality of communication specificity was included in the sense that the more direct connections an individual has to maintain with other individuals, the less she is able to specify her attention per link within her total time available. Therefore, her additive value for others declines with an increasing number of links, and she also derives less additive value from others with an increasing number of links. Second, a distinction was made between the social and informational value of communication, where informational value is assumed to be transferable via indirect links, whereas social value is not transferable. Analytical results derived by using the concept of pairwise stability showed a tendency towards fragmented pairwise stable structures consisting of small, disjoint (star) components - which can be attributed to the joint effect of the two aspects mentioned. Finally, it was shown that only some of the pairwise stable structures provide optimal welfare (total payoffs), and that the relative focus on informational versus social value of communication affects this welfare. 
Further research could study the sets of pairwise stable and efficient network structures with other functional forms to model specificity. In the model of this paper the specificity property of communication is such that value is divided proportionally by the number of links that agents face, whereas other forms of specificity might be applicable to other communication forms. For example, agents may have economies of scale in coping with several links. A functional form which captures this phenomenon would for instance be given by

$$
\begin{aligned}
\Pi_{i}(g)= & \alpha \sum_{j \in N_{i}(g)} \sum_{p \in \mathcal{P}_{i, j}(g)} \frac{V^{\mathrm{i}}}{\sqrt{\mu_{i}^{\mathrm{l}}(g)} \cdot \sqrt{\mu_{j}^{\mathrm{l}}(g)} \cdot \prod_{k \in \breve{P}_{i, j}(p ; g)} \mu_{k}^{\mathrm{l}}(g)} \\
& +(1-\alpha) \sum_{j \in N_{i}^{1}(g)} \frac{V^{\mathrm{s}}}{\sqrt{\mu_{i}^{\mathrm{l}}(g)} \cdot \sqrt{\mu_{j}^{\mathrm{l}}(g)}} .
\end{aligned}
$$

With this payoff function, the three-agent star component is not pairwise stable anymore, for the two periphery agents both benefit from creating a link between them. Indeed, payoffs with and without the link are

$$
\begin{array}{r}
\alpha V^{\mathrm{i}}\left(\frac{1}{2}+\frac{1}{4}+\frac{1}{2}+\frac{1}{4}\right)+(1-\alpha) V^{\mathrm{s}}\left(\frac{1}{2}+\frac{1}{2}\right) \\
>\alpha V^{\mathrm{i}}\left(\frac{1}{\sqrt{2}}+\frac{1}{2}\right)+(1-\alpha) V^{\mathrm{s}}\left(\frac{1}{\sqrt{2}}\right) .
\end{array}
$$

In general, economies of scale in coping with several links will diminish the fragmentation caused by full specificity.

The stability concept used here was pairwise stability. Alternatively, the model could be analyzed by applying the Nash concept, which assumes stability against single-agent deviations of more than one link. If the strategies $g_{i, j}$ indicate with a zero or a one whether $i$ wants to be directly linked to $j$ or not and again the actual links $\bar{g}_{i, j}=\min \left\{g_{i, j}, g_{j, i}\right\}$ are 
only formed if both agents want the link, the payoff function can be written as

$$
\begin{aligned}
\Pi_{i}(g)= & \alpha \sum_{j \in N_{i}(\bar{g})} \sum_{p \in \mathcal{P}_{i, j}(\bar{g})} \frac{V^{\mathrm{i}}}{\mu_{i}^{\mathrm{N}}(\bar{g}) \cdot \mu_{j}^{\mathrm{N}}(\bar{g}) \cdot \prod_{k \in \breve{P}_{i, j}(p ; \bar{g})}\left(\mu_{k}^{\mathrm{N}}(\bar{g})\right)^{2}} \\
& +(1-\alpha) \sum_{j \in N_{i}^{\mathrm{N}}(\bar{g})} \frac{V^{\mathrm{s}}}{\mu_{i}^{\mathrm{N}}(\bar{g}) \cdot \mu_{j}^{\mathrm{N}}(\bar{g})} .
\end{aligned}
$$

Now $\bar{g}$ is defined to be a Nash network if it is supported by some $g$ from which no single agent can change her strategies such that she strictly improves her payoff. If $n=3$, all possible structures except for the complete one are Nash networks. For example, the empty network is Nash since it is supported by the strategies $g_{i, j}=0$ for all $i$ and $j$, even though agents would obviously benefit by changing their strategies simultaneously. Further research could look for a refinement of the Nash concept such that this extreme coordination problem would not take place.

The outcome variable focused on here was the overall welfare level. It may also be interesting from both a theoretical and a managerial point of view, to study the structural effects on the actual product-, service-, or firm-related information exchanged, thus disregarding the value derived from the social aspects of communication.

The informational versus social orientation appeared to be of managerial concern here. The model can be extended to allow for investigating the effectiveness of other community design issues, like introducing an expert or a social animator in the OCCN, who possibly does not even act strategically in the link formation game. Therefore, future research could introduce valuation heterogeneity in the sense that agents represent different values for their fellow customers (quality heterogeneity) or have different opinions on the values of their fellow customers (judgement heterogeneity) (e.g., Haller and Sarangi, 2003).

Thus, we hope that our current work stimulates future research in the exciting area of 
OCCNs and the role of balancing social and informational value in these communication networks.

\section{References}

[1] Ahuja, M.K. and Carley, K.M. (1999), "Network Structure in Virtual Organizations", Organization Science 10(6), 741-757.

[2] Algesheimer, R., Dholakia, U.M. and Herrmann, A. (2005), "The Social Influence of Brand Community: Evidence from European Car Clubs", Journal of Marketing 69(3), $19-34$.

[3] Asvanund, A., Clay, K., Krishnan, R. and Smith, M.D. (2004), "An Empirical Analysis of Network Externalities in Peer-to-Peer Music-Sharing Networks", Information Systems Research 15(2), 155-174.

[4] Bagozzi, R.P. and Dholakia, U.M. (2002), "Intentional Social Action in Virtual Communities", Journal of Interactive Marketing 16(2), 2-21.

[5] Bala, V. and Goyal, S. (2000), "A Noncooperative Model of Network Formation", Econometrica 68(5), 1181-1229.

[6] Butler, B.S. (2001), "Membership Size, Communication Activity, and Sustainability: A Resource-Based Model of Online Social Structures", Information Systems Research 12(4), 346-362. 
[7] Currarini, S. (2002), "Stable Organizations with Externalities", Fondazione Eni Enrico Mattei Nota di Lavoro, Coalition Theory Series 51.

[8] Dellarocas, C. (2003), "The Digitization of Word of Mouth: Promise and Challenges of Online Feedback Mechanisms", Management Science 49(10), 1407-1424.

[9] Dholakia, U.M., Bagozzi, R.P. and Klein Pearo, L. (2004), "A Social Influence Model of Consumer Participation in Network- and Small-Group-Based Virtual Communities", International Journal of Research in Marketing 21(3), 241-263.

[10] Goyal, S. and Vega-Redondo, F. (2004), "Structural Holes in Social Networks", working paper.

[11] Hagel, J. III and Armstrong, A.G. (1997), Net Gain: Expanding Markets Through Virtual Communities, Boston MA: HBS press.

[12] Haller, H. and Sarangi, S. (2003), "Nash Networks with Heterogeneous Agents", DIW Berlin German Institute for Economic Research, Discussion Papers 337.

[13] Hennig-Thurau, T., Gwinner, K.P., Walsh, G. and Gremler, D.D. (2004), "Electronic Word-Of-Mouth via Consumer-Opinion Platforms: What Motivates Consumers to Articulate Themselves on the Internet?", Journal of Interactive Marketing 18(1), 38-52.

[14] Jackson, M.O. and Wolinsky, A. (1996), "A Strategic Model of Social and Economic Networks", Journal of Economic Theory 71(1), 44-74.

[15] Kvassov, D. (2002), "Formation of Networks: Competition and Specificity", working paper Department of Economics, University of Auckland. 
[16] Lipnack, J. and Stamps, J. (2000), Virtual Teams: People Working Across Boundaries with Technology, 2nd edition, New York: John Wiley.

[17] McLure Wasko, M. and Faraj, S. (2005), "Why Should I Share? Examining Social Capital and Knowledge Contribution in Electronic Networks of Practice", MIS Quarterly 29(1), 35-57.

[18] Qin, C.-Z. (1996), "Endogenous Formation of Cooperation Structures", Journal of Economic Theory 69(1), 218-226.

[19] Wellman, B., Salaff, J., Dimitrova, D., Garton, L., Gulia, M. and Haythornthwaite, C. (1996), "Computer Networks as Social Networks: Collaborative Work, Telework, and Virtual Community", Annual Review of Sociology 22(1), 213-238. 